Article

\title{
High-Pressure Structural Behavior and Equation of State of Kagome Staircase Compound, $\mathrm{Ni}_{3} \mathrm{~V}_{2} \mathrm{O}_{8}$
}

\author{
Daniel Diaz-Anichtchenko $^{1}{ }^{\circledR}$, Robin Turnbull ${ }^{1}\left(\mathbb{D}\right.$, Enrico Bandiello ${ }^{1}\left(\mathbb{D}\right.$, Simone Anzellini $^{2}(\mathbb{D}$ \\ and Daniel Errandonea $1, * \mathbb{D}$ \\ 1 Departamento de Física Aplicada-ICMUV, Universitat de València, Dr. Moliner 50, 46100 Burjassot, Spain; \\ daniel.diaz@uv.es (D.D.-A.); robin.turnbull@uv.es (R.T.); enrico.bandiello@uv.es (E.B.) \\ 2 Diamond Light Source Ltd., Diamond House, Harwell Science and Innovation Campus, Didcot, \\ Oxfordshire OX11 0DE, UK; simone.anzellini@diamond.ac.uk \\ * Correspondence: daniel.errandonea@uv.es
}

Received: 17 September 2020; Accepted: 5 October 2020; Published: 8 October 2020

\begin{abstract}
We report on high-pressure synchrotron X-ray diffraction measurements on $\mathrm{Ni}_{3} \mathrm{~V}_{2} \mathrm{O}_{8}$ at room-temperature up to $23 \mathrm{GPa}$. According to this study, the ambient-pressure orthorhombic structure remains stable up to the highest pressure reached in the experiments. We have also obtained the pressure dependence of the unit-cell parameters, which reveals an anisotropic compression behavior. In addition, a room-temperature pressure-volume third-order Birch-Murnaghan equation of state has been obtained with parameters: $V_{0}=555.7(2) \AA^{3}, K_{0}=139(3) \mathrm{GPa}$, and $K_{0}{ }^{\prime}=4.4(3)$. According to this result, $\mathrm{Ni}_{3} \mathrm{~V}_{2} \mathrm{O}_{8}$ is the least compressible kagome-type vanadate. The changes of the crystal structure under compression have been related to the presence of a chain of edge-sharing $\mathrm{NiO}_{6}$ octahedral units forming kagome staircases interconnected by $\mathrm{VO}_{4}$ rigid tetrahedral units. The reported results are discussed in comparison with high-pressure X-ray diffraction results from isostructural $\mathrm{Zn}_{3} \mathrm{~V}_{2} \mathrm{O}_{8}$ and density-functional theory calculations on several isostructural vanadates.
\end{abstract}

Keywords: vanadate; kagome compound; high pressure; X-ray diffraction; equation of state

\section{Introduction}

Metal orthovanadates with formula $\mathrm{M}_{3} \mathrm{~V}_{2} \mathrm{O}_{8}$, where $\mathrm{M}$ is a divalent metal, have been the focus of research in recent years, mainly because of their optical, dielectric, and magnetic properties [1-4]. These properties make the $\mathrm{M}_{3} \mathrm{~V}_{2} \mathrm{O}_{8}$ family of compounds useful in several technological applications, from photocatalytic water splitting [3] to light-emitting diodes [5] and ion batteries [6]. In addition, compounds such as $\mathrm{Co}_{3} \mathrm{~V}_{2} \mathrm{O}_{8}$ and $\mathrm{Ni}_{3} \mathrm{~V}_{2} \mathrm{O}_{8}$ have very interesting magnetic and ferroelastic properties [2], which are intimately related to the presence of kagome staircase two-dimensional (2D) magnetic layers [2].

$\mathrm{M}_{3} \mathrm{~V}_{2} \mathrm{O}_{8}$ compounds are also intriguing from a crystallographic perspective [7,8]. They share a particular type of crystal structure, which is shown schematically in Figure 1. The structure is orthorhombic (space group Cmca, No. 64) with eight formula units per unit cell. In the crystal structure, the $\mathrm{M}$ atoms are octahedrally coordinated by oxygen atoms (see Figure 1a). In particular, the $\mathrm{MO}_{6}$ octahedral units exhibit an edge-sharing pattern, forming a quasi-planar kagome staircase (see Figure 1b), which, in the case of $\mathrm{Ni}_{3} \mathrm{~V}_{2} \mathrm{O}_{8}$, results in inequivalent super-exchange interactions within the magnetic lattice [9]. Consequently, an anisotropic magnetic coupling develops in the stair-like kagome layers, leading to the emergence of multiple temperature-induced magnetic phase transitions [9]. The kagome staircases are separated by $\mathrm{VO}_{4}$ tetrahedral units, giving the $\mathrm{M}_{3} \mathrm{~V}_{2} \mathrm{O}_{8}$ family of compounds a pseudo-two-dimensional layered characteristic, which, as discussed below, leads to an anisotropic compressional behavior when an external pressure is applied. 
$\mathrm{AVO}_{4}$ orthovanadates, where $\mathrm{A}$ is a trivalent atom, have been extensively studied under high-pressure (HP) conditions [10,11]. As a result, first-order phase transitions, involving large volume changes, have been discovered at pressures below $10 \mathrm{GPa}$ (for instance, the zircon-scheelite and zircon-monazite transitions in alkaline earth vanadates $[10,11])$. Many of these transitions lead to interesting phenomena such as a collapse of the electronic band gap [12]. In contrast, very little effort has been dedicated to study kagome staircase orthovanadates under HP. Indeed, only two works can be found in the literature [7,9]. One of them reports powder X-ray diffraction (XRD) data on $\mathrm{Zn}_{3} \mathrm{~V}_{2} \mathrm{O}_{8}$ up to $15 \mathrm{GPa}$ [7]. No phase transition was detected and an anisotropic response to compression was determined. The second one reports the influence of pressure on the magnetic properties of $\mathrm{Ni}_{3} \mathrm{~V}_{2} \mathrm{O}_{8}$ up to 2 Gpa [9]. Therefore, despite the interesting physics involved, the HP behavior of $\mathrm{M}_{3} \mathrm{~V}_{2} \mathrm{O}_{8}$ orthovanadates is an underexplored research area.

Here, we report a study of the HP behavior of the structural properties of $\mathrm{Ni}_{3} \mathrm{~V}_{2} \mathrm{O}_{8}$. The information obtained from such studies can form a foundation for future studies on the influence of pressure in physical properties, including magnetic properties. We have performed synchrotron powder XRD experiments in $\mathrm{Ni}_{3} \mathrm{~V}_{2} \mathrm{O}_{8}$ up to $23 \mathrm{Gpa}$ at ambient temperature, thereby obtaining information on the structural stability of compressibility of the compound. The rest of the paper is organized as follows. Section 2 is devoted to the description the experimental methods. In Section 3, the results are reported and discussed in comparison with $\mathrm{Zn}_{3} \mathrm{~V}_{2} \mathrm{O}_{8}$ and other isostructural $\mathrm{M}_{3} \mathrm{~V}_{2} \mathrm{O}_{8}$ vanadates. Concluding remarks are given in Section 4.

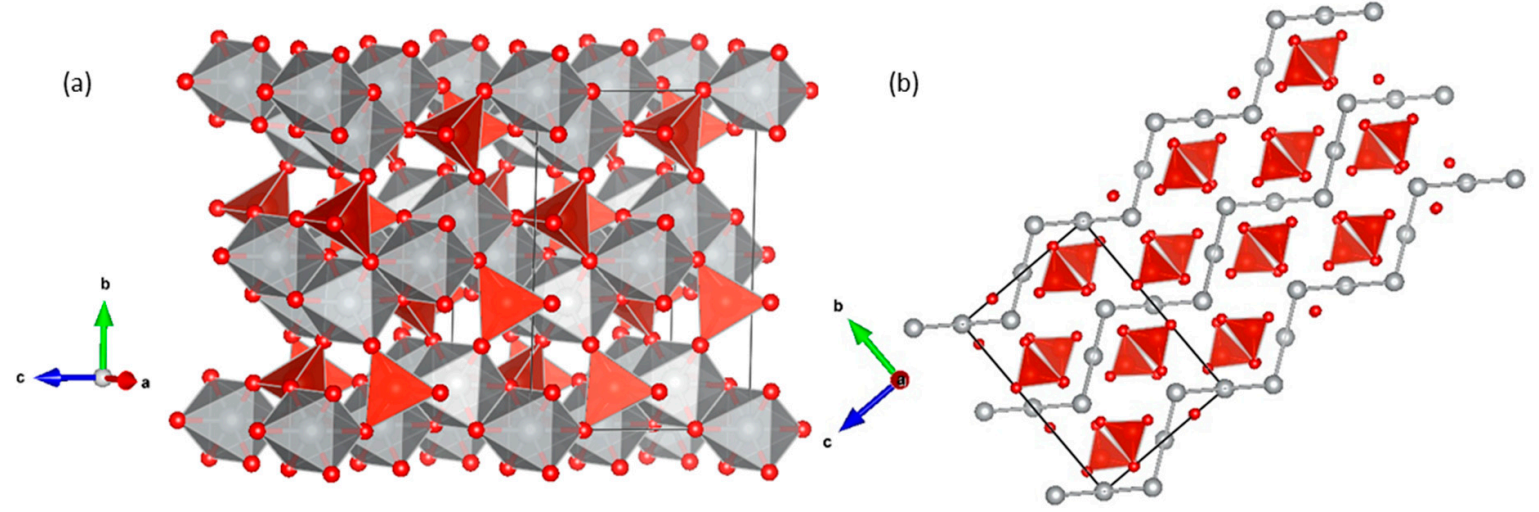

Figure 1. (a) Crystal structure of $\mathrm{Ni}_{3} \mathrm{~V}_{2} \mathrm{O}_{8}$. $\mathrm{NiO}_{6}$ octahedra are shown in grey and $\mathrm{VO}_{4}$ tetrahedra are in red. Small red circles are oxygen atoms. (b) Projection of the crystal structure showing $\mathrm{VO}_{4}$ tetrahedra (in red) and $\mathrm{Ni}$ atoms (in gray) connected to make more evident the kagome staircase framework. Three unit cells are included in (b). The unit cell is shown is black solid lines.

\section{Materials and Methods}

Powder samples of $\mathrm{Ni}_{3} \mathrm{~V}_{2} \mathrm{O}_{8}$ were synthesized via a solid-state reaction starting from $\mathrm{NiO}(99.995 \%$ purity) and $\mathrm{V}_{2} \mathrm{O}_{5}$ (99.9\% purity). The starting reagents were obtained from Alfa Aesar (Tewksbury, MA, United States). They were mixed meticulously and subsequently heated in an $\mathrm{Al}_{2} \mathrm{O}_{3}$ crucible in air at $800^{\circ} \mathrm{C}$ for $16 \mathrm{~h}$. The product was then ground and pressed into a pellet, to be afterward sintered at $900{ }^{\circ} \mathrm{C}$ for an additional $16 \mathrm{~h}$. The obtained sample was finally ground manually in an agate mortar to obtain a micron size powder. In order to characterize it, we performed powder XRD measurements using a X'Pert Pro diffractometer from Panalytical (Almelo, The Netherlands) with $\mathrm{Cu} \mathrm{K}_{\alpha 1}$ radiation $\left(\lambda=1.5406 \AA\right.$ ). The measurements were performed in the angular range $10^{\circ}<2 \theta<70^{\circ}$, by continuous scanning with a step size of $0.02^{\circ}$ and total step time of $200 \mathrm{~s}$.

Angle-dispersive $\mathrm{X}$-ray diffraction experiments at room-temperature and high pressure were performed at beamline I15 of the Diamond Light Source using a membrane-type diamond-anvil cell (DAC) with diamond-culet sizes of $450 \mu \mathrm{m}$ in diameter and monochromatic X-rays of $\lambda=0.42466 \AA$. The X-ray beam was focused down to $10 \times 10 \mu \mathrm{m}^{2}$. A rocking $\left( \pm 10^{\circ}\right)$ of the DAC was used to improve the 
homogeneity of the Debye rings. A fine powder of $\mathrm{Ni}_{3} \mathrm{~V}_{2} \mathrm{O}_{8}$ was loaded in a $150 \mu \mathrm{m}$ hole of a rhenium gasket pre-indented to a $40 \mu \mathrm{m}$ thickness. One grain of $\mathrm{Cu}$ was loaded together with the sample and used as internal standard for pressure determination. For this purpose, we used the equation of state (EOS) determined by Dewaele et al. under hydrostatic conditions [13]. A 16:3:1 methanol-ethanol-water (MEW) mixture was used as a pressure-transmitting medium [14,15]. The powder XRD patterns were collected using a Pilatus 2M detector (DECTRIS, Baden, Switzerland) and transformed into one-dimensional patterns using the DIOPTAS suite [16]. The sample-to-detector distance was measured following standard procedure from the diffraction rings of $\mathrm{LaB}_{6}$.

\section{Results and Discussion}

The results of the ambient-conditions XRD measurements are shown in Figure 2. All of the observed reflections can be accounted for by the orthorhombic crystal structure reported in the literature (space group Cmca, No. 64) [17], leading to small residuals (see Figure 2) and converging to small R-factors: $R_{\mathrm{p}}=2.39 \%$ and $\mathrm{R}_{\mathrm{WP}}=3.79 \%$. The resulting unit-cell parameters were $a=5.928(4) \AA$, $b=11.384(6) \AA$, and $c=8.241(5) \AA$, which agree to within $0.1 \%$ of literature values [17]. The obtained atomic positions are reported in Table 1, being also in good agreement with the literature [17].

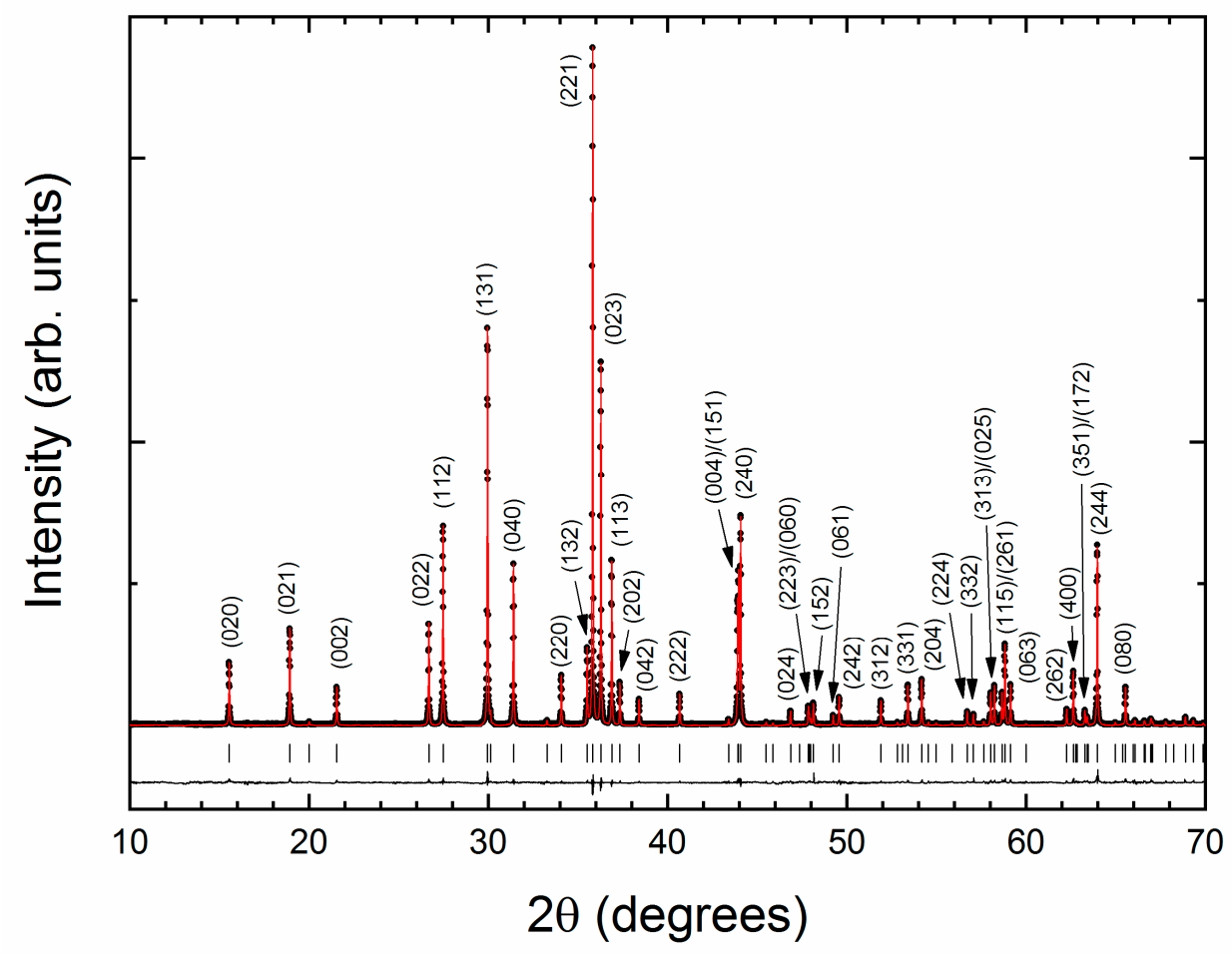

Figure 2. Background subtracted ambient-conditions powder X-ray diffraction (XRD) pattern measured in $\mathrm{Ni}_{3} \mathrm{~V}_{2} \mathrm{O}_{8}$ using $\mathrm{Cu} \mathrm{K}_{\alpha 1}$. Experiment: black dots, Rietveld refinement: red line, residual: black line. Ticks indicate the position of peaks. The most intense peaks have been labeled with the corresponding Bragg planes.

Table 1. Fractional coordinates of atoms in the crystal structure of $\mathrm{Ni}_{3} \mathrm{~V}_{2} \mathrm{O}_{8}$.

\begin{tabular}{ccccc}
\hline Atom & Wyckoff Position & $\mathbf{x}$ & $\mathbf{y}$ & $\mathbf{z}$ \\
\hline $\mathrm{Ni}_{1}$ & $4 \mathrm{a}$ & 0 & 0 & 0 \\
$\mathrm{Ni}_{2}$ & $8 \mathrm{e}$ & 0.25 & $0.1319(4)$ & 0.25 \\
$\mathrm{~V}$ & $8 \mathrm{f}$ & 0 & $0.3766(5)$ & $0.1191(5)$ \\
$\mathrm{O}_{1}$ & $8 \mathrm{f}$ & 0 & $0.2491(9)$ & $0.2302(9)$ \\
$\mathrm{O}_{2}$ & $8 \mathrm{f}$ & 0 & $0.0011(9)$ & $0.2445(9)$ \\
$\mathrm{O}_{3}$ & $16 \mathrm{~g}$ & $0.2663(9)$ & $0.1193(9)$ & $0.0009(9)$ \\
\hline
\end{tabular}


Figures 3-5 show sequential integrated XRD patterns acquired up to $23 \mathrm{GPa}$ on compression of $\mathrm{Ni}_{3} \mathrm{~V}_{2} \mathrm{O}_{8}$. In Figure 3, it can be seen that over the complete pressure range of the experiments, all the reflections can be assigned to the known orthorhombic structure of $\mathrm{Ni}_{3} \mathrm{~V}_{2} \mathrm{O}_{8}$ and to $\mathrm{Cu}$ (the pressure marker), which is supported by a profile matching analysis using the Le Bail method. Therefore, no phase transition is observed in $\mathrm{Ni}_{3} \mathrm{~V}_{2} \mathrm{O}_{8}$ up to $23 \mathrm{GPa}$. More details of the HP X-ray patterns can be seen in Figures 4 and 5. Figure 4 shows results for $\mathrm{P} \leq 7 \mathrm{GPa}$ and Figure 5 shows results from 7.6 to $23 \mathrm{GPa}$. Beyond $20 \mathrm{GPa}$, we detected the presence of one extra reflection originating from the Re gasket, which appears because of the reduction in the size of the sample chamber. The data in Figures 3 and 4 show a change of relative peak intensities under increasing compression. This is related to the development of preferred crystallite orientation relative to the X-ray beam. Under compression, we also observe that the position of peaks indexed as $0 k 0$ is less sensitive to pressure, and that they move less towards higher angles than the rest of the peaks. This can be observed in Figure 4 by comparing the pressure evolution of peaks identified with planes (131) and (040), since the (131) peak approaches the stationary (040) peak. As we will discuss below, this observation is rooted in the non-isotropic behavior of $\mathrm{Ni}_{3} \mathrm{~V}_{2} \mathrm{O}_{8}$. Another consequence of the anisotropic behavior is the gradual merging of peaks; for instance, those identified with planes (221) and (023). Their merging under compression can be seen in Figure 3, Figure 4, and Figure 5. In addition, beyond 7.6 GPa, we have observed a gradual broadening of the peaks (Figure 5), which is related to the gradual loss of quasi-hydrostaticity [15,18].

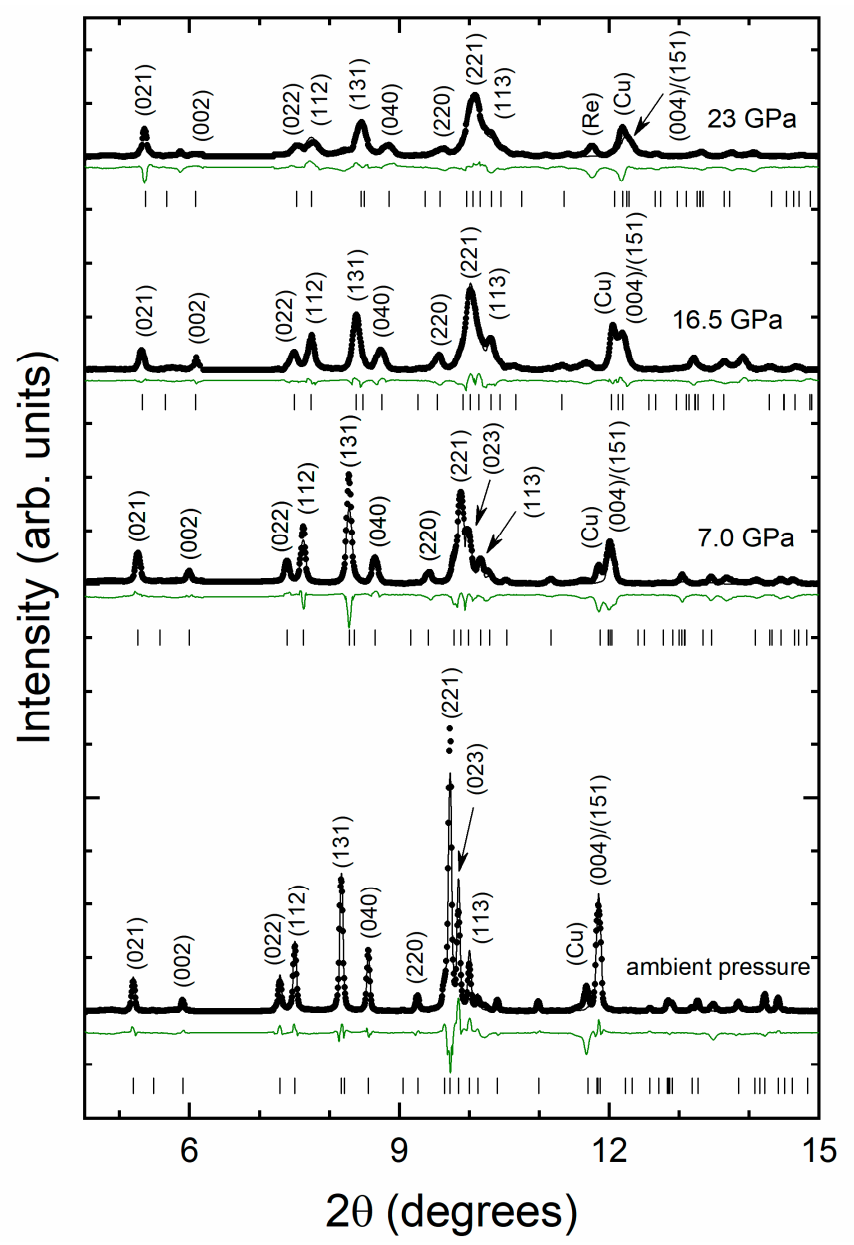

Figure 3. Integrated XRD patterns of $\mathrm{Ni}_{3} \mathrm{~V}_{2} \mathrm{O}_{8}$ from 0 to $23 \mathrm{GPa}$. Pressures are indicated on each pattern and the Bragg planes corresponding to the most intense reflections have been labeled. The experiments are shown with symbols. The refinements, assuming the ambient-pressure orthorhombic structure, are shown with black lines. The difference between the observed data and Le Bail refinement is shown in green. Ticks indicate the positions of $\mathrm{Ni}_{3} \mathrm{~V}_{2} \mathrm{O}_{8}$ peaks. 


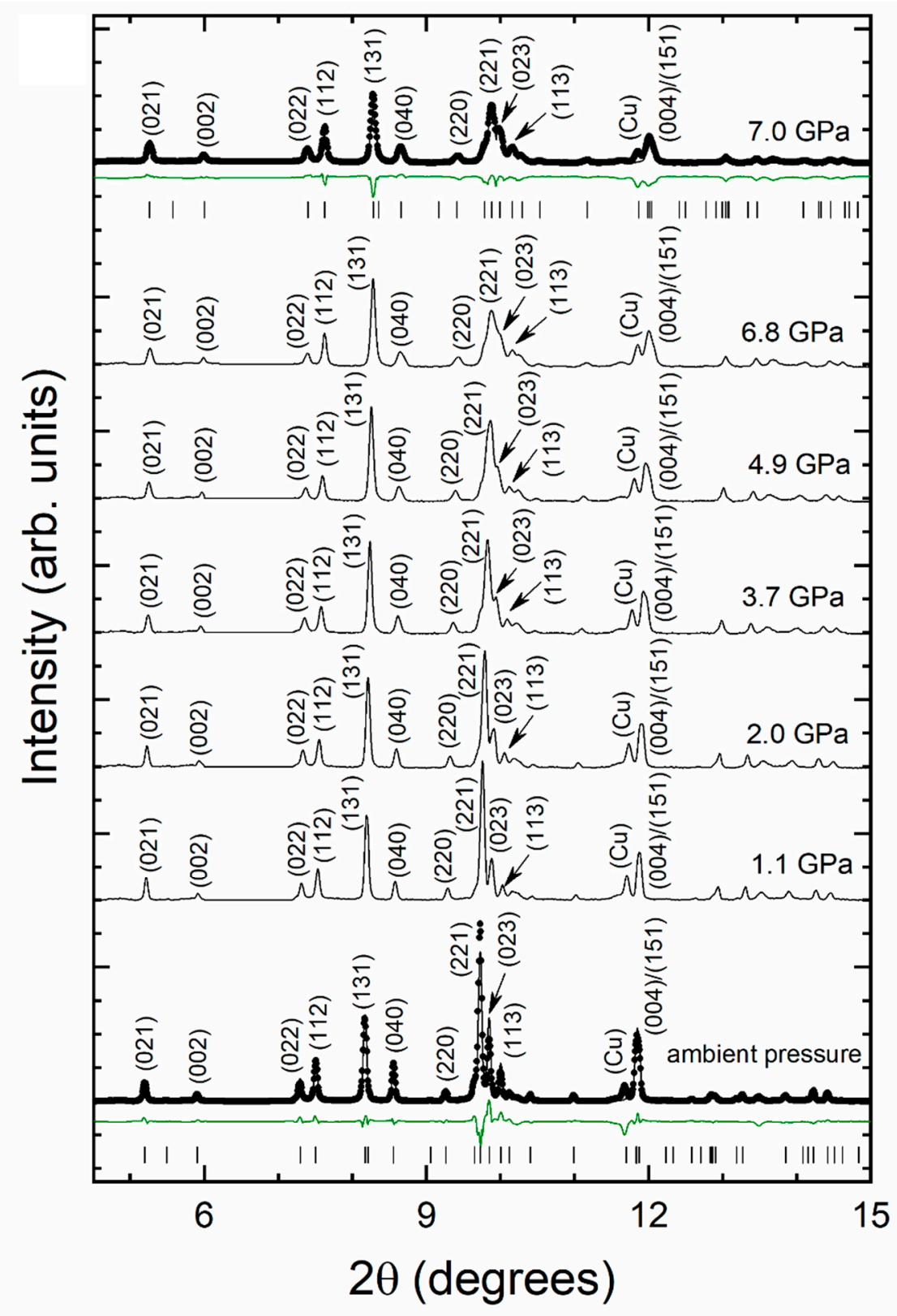

Figure 4. Integrated $X R D$ patterns of $\mathrm{Ni}_{3} \mathrm{~V}_{2} \mathrm{O}_{8}$ measured from 0 to $7 \mathrm{GPa}$. Pressures are indicated on each pattern and Bragg planes corresponding to the most intense reflections have been labeled. At the bottom and top, traces observed experimental data are shown with black symbols. The refinements are shown with black lines. The difference between the observed data and Le Bail refinement is shown in green.

Through performing Le Bail refinements of the powder XRD patterns, we have obtained the pressure dependence of the unit-cell parameters. The XRD patterns at all pressures can be identified with the ambient-pressure orthorhombic structure of $\mathrm{Ni}_{3} \mathrm{~V}_{2} \mathrm{O}_{8}$; however, the XRD patterns measured at pressures higher than $15.1 \mathrm{GPa}$ have been excluded from this analysis due to the partial overlap of the $\mathrm{Cu}$ peak used to determine pressure with a diffraction peak from the sample (see Figure 5), because this could lead to inaccuracies in the pressure determination larger than $0.2 \mathrm{GPa}$. The unit-cell parameters as a function of pressure are shown in Figure 6. This information is important for modeling the suppression of ferroelectricity by pressure in $\mathrm{Ni}_{3} \mathrm{~V}_{2} \mathrm{O}_{8}$ [9]. The response of the crystal structure to compression is clearly non-isotropic, with the $b$ and $a$ axes, respectively, having the smallest and largest compressibility. The anisotropic compressibility observed $\mathrm{Ni}_{3} \mathrm{~V}_{2} \mathrm{O}_{8}$ is fully compatible with the 
anisotropic thermal expansion of the same compound [9]. Both results can be rationalized based on the layered characteristic of the kagome staircase in the crystal structure and the relative compressibilities of the constituent polyhedra, as discussed below.

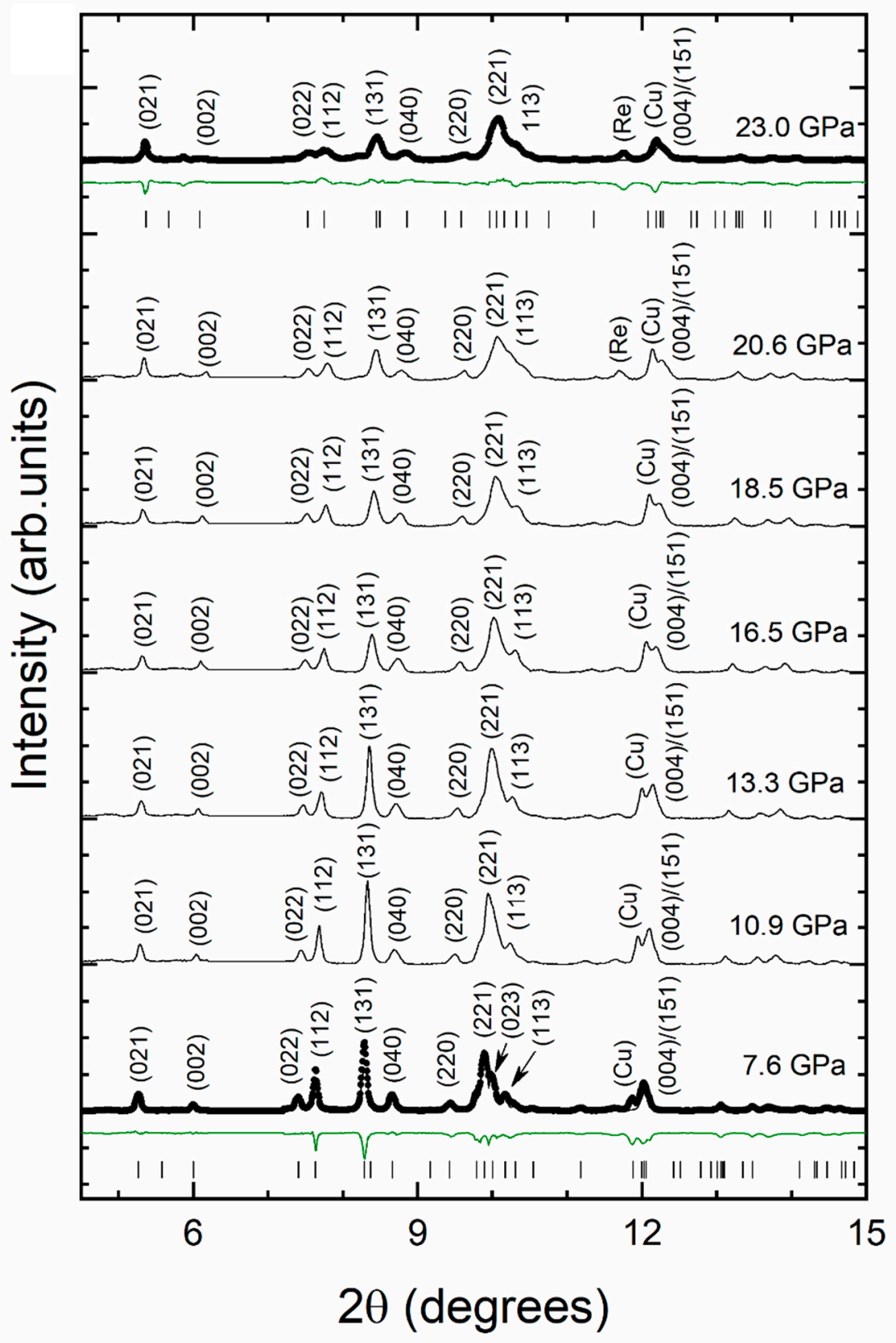

Figure 5. Integrated XRD patterns of $\mathrm{Ni}_{3} \mathrm{~V}_{2} \mathrm{O}_{8}$ measured from 7.6 to $23 \mathrm{GPa}$. Pressures are indicated on each pattern, and Bragg planes corresponding to the most intense reflections have been labeled. At the bottom and top, traces observed experimental data are shown with black symbols. The refinements are shown with black lines. The difference between the observed data and Le Bail refinement is shown in green. In the figure, it can be clearly seen the merging and broadening of peaks described in the text.

From the hydrostatic pressure range of our experiments ( $P \leq 7.6 \mathrm{GPa}$ ), we have determined the linear compressibilities at ambient pressure, $\kappa_{x}=-\frac{1}{x} \frac{\partial x}{\partial P}$, where $x$ represents the unit cell lengths $a, b$, or $c$. The linear compressibilities are summarized in Table 2, where it can be seen that they increase following the sequence $\kappa_{b}<\kappa_{c}<\kappa_{a}$. The $a$ and $c$-axes have larger compressibilities than the $b$-axis by approximate factors of 1.5 and 1.3, respectively. A similar behavior has previously been observed in $\mathrm{Zn}_{3} \mathrm{~V}_{2} \mathrm{O}_{8}$. 


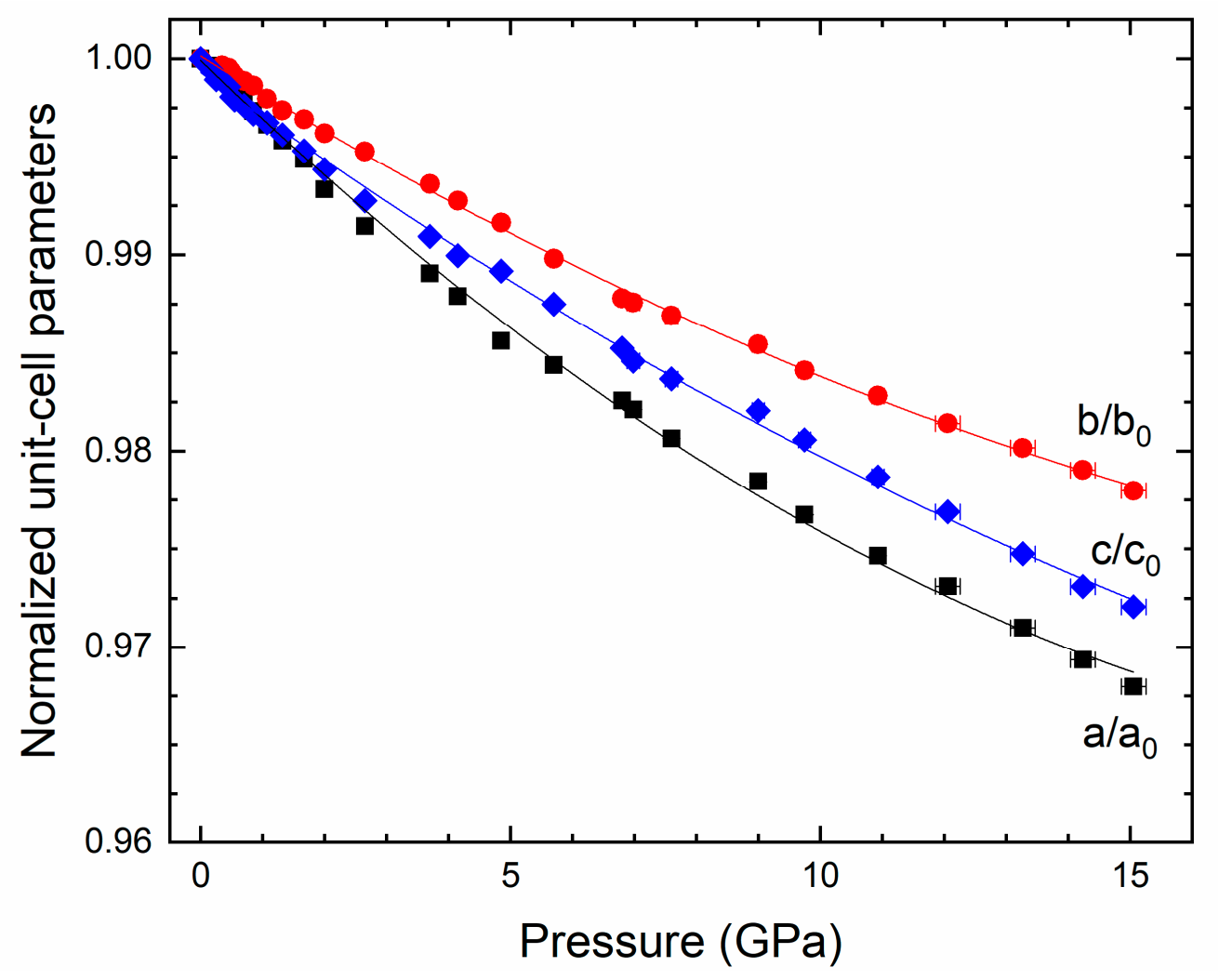

Figure 6. Normalized unit-cell parameters of $\mathrm{Ni}_{3} \mathrm{~V}_{2} \mathrm{O}_{8}$ as a function of pressure. Symbols are the results from Le Bail refinements. The lines describe unidirectional equations of state (EOSs) described in the text. Where not shown error bars are comparable to symbols' size.

The reason for the anisotropic behavior of $\mathrm{Ni}_{3} \mathrm{~V}_{2} \mathrm{O}_{8}$ and $\mathrm{Zn}_{3} \mathrm{~V}_{2} \mathrm{O}_{8}$ (and probably all isomorphic vanadates) might be related to the kagome layered characteristic of the crystal structure. It is well-known that in other ternary oxides, such as $\mathrm{NiWO}_{4}$ and $\mathrm{ZnWO}_{4}$ [19], the pressure-induced changes in crystal structure are largely determined by the $\mathrm{NiO}_{6}$ and $\mathrm{ZnO}_{6}$ octahedral units because of their large compressibility relative to the $\mathrm{VO}_{4}$ tetrahedron. The much smaller $\mathrm{VO}_{4}$ tetrahedron has been determined from the study of many different vanadates to be an essentially rigid unit, which, due to $\mathrm{V}$ $3 \mathrm{~d}-\mathrm{O} 2 \mathrm{p}$ hybridization [20], changes little under compression [10]. As we have already described (see Figure 1), the crystal structure of $\mathrm{M}_{3} \mathrm{~V}_{2} \mathrm{O}_{8}$ compounds is composed of 2D kagome staircases of compressible $\mathrm{MO}_{6}$ octahedra, which therefore constitute compressible layers that lie perpendicular to the $b$-axis. In between these layers of $\mathrm{NiO}_{6}$ and $\mathrm{ZnO}_{6}$ octahedra, there are located the less compressible $\mathrm{VO}_{4}$ tetrahedra, which are arranged to form pillars between the kagome layers, reducing the compressibility along the $b$-axis. In fact, the in-plane effective bulk modulus [21] for kagome layers is $132 \mathrm{GPa}$, and the effective bulk modulus in the perpendicular direction is $186 \mathrm{GPa}$. Thus, the layered characteristic of the crystal structure of kagome-type vanadates provides a rational explanation to their anisotropic behavior under compression. The present results suggest that it is not unreasonable to speculate that anisotropic compressibility would be a finger print of the broad family of kagome-type compounds. Such anisotropic behavior is expected to affect super-exchange interactions between magnetic atoms, thereby modifying the temperature of different magnetic transitions. This would modify the Néel temperature as reported for $\mathrm{Ni}_{3} \mathrm{~V}_{2} \mathrm{O}_{8}$ [9]. By extrapolating the result reported by Chaudhury et al. [9], it can be speculated that under compression the Néel temperature can be increased from $9.8 \mathrm{~K}$ at ambient pressure to a temperature close to $15 \mathrm{~K}$ at $20 \mathrm{GPa}$. 
Table 2. Linear compressibilities at zero pressure (left) and room-temperature equation of state (EOS) parameters of $\mathrm{Ni}_{3} \mathrm{~V}_{2} \mathrm{O}_{8}$. The center (right) column shows the converged fitting parameters for the third-order Birch-Murnaghan EOS for $P \leq 7.6$ (15.1) GPa. $V_{0}$ is the ambient-pressure volume. $K_{0}$ is the bulk modulus. $K_{0}{ }^{\prime}$ is the pressure derivative of the bulk modulus.

\begin{tabular}{ccc}
\hline$\kappa_{\mathrm{a}}=2.7(1) 10^{-3} \mathrm{GPa}^{-1}$ & $V_{0}=555.7(2) \AA^{3}$ & $V_{0}=555.5(2) \AA^{3}$ \\
\hline$\kappa_{\mathrm{b}}=1.79(6) 10^{-3} \mathrm{GPa}^{-1}$ & $K_{0}=139(3) \mathrm{GPa}$ & $K_{0}=118(1) \mathrm{GPa}$ \\
\hline$\kappa_{\mathrm{c}}=2.33(5) 10^{-3} \mathrm{GPa}^{-1}$ & $K_{0}{ }^{\prime}=4.4(3)$ & $K_{0}{ }^{\prime}=11.1(9)$ \\
\hline
\end{tabular}

The unit-cell volume of $\mathrm{Ni}_{3} \mathrm{~V}_{2} \mathrm{O}_{8}$ as a function of pressure is shown in Figure 7. The results show an apparent change in compressibility at $7.6 \mathrm{GPa}$, which cannot be related to a phase transition, since the XRD data provide no evidence for it up to the maximum pressure investigated (23 GPa). A similar behavior has been recently reported in other ternary oxides near this pressure [22]. The apparent change in compressibility is in fact related to the known hydrostatic limit for MEW [15]. Fitting a third-order Birch-Murnaghan (BM) EOS [23] (using EosFit [24]) in the hydrostatic regime ( $P \leq 7.6 \mathrm{GPa}$ ) gives the parameters given in the central column of Table 2 . To illustrate the importance of constraining EOS fits to hydrostatic data, for comparison, we also fitted the EOS with all data up to $15.1 \mathrm{GPa}$, leading to the values given in the right column of Table 2. The inclusion of non-hydrostatic data leads to an underestimation of the ambient pressure bulk modulus $\left(K_{0}\right)$ and to an unusual large pressure derivative $\left(K_{0}{ }^{\prime}=11.1(9)\right)$.

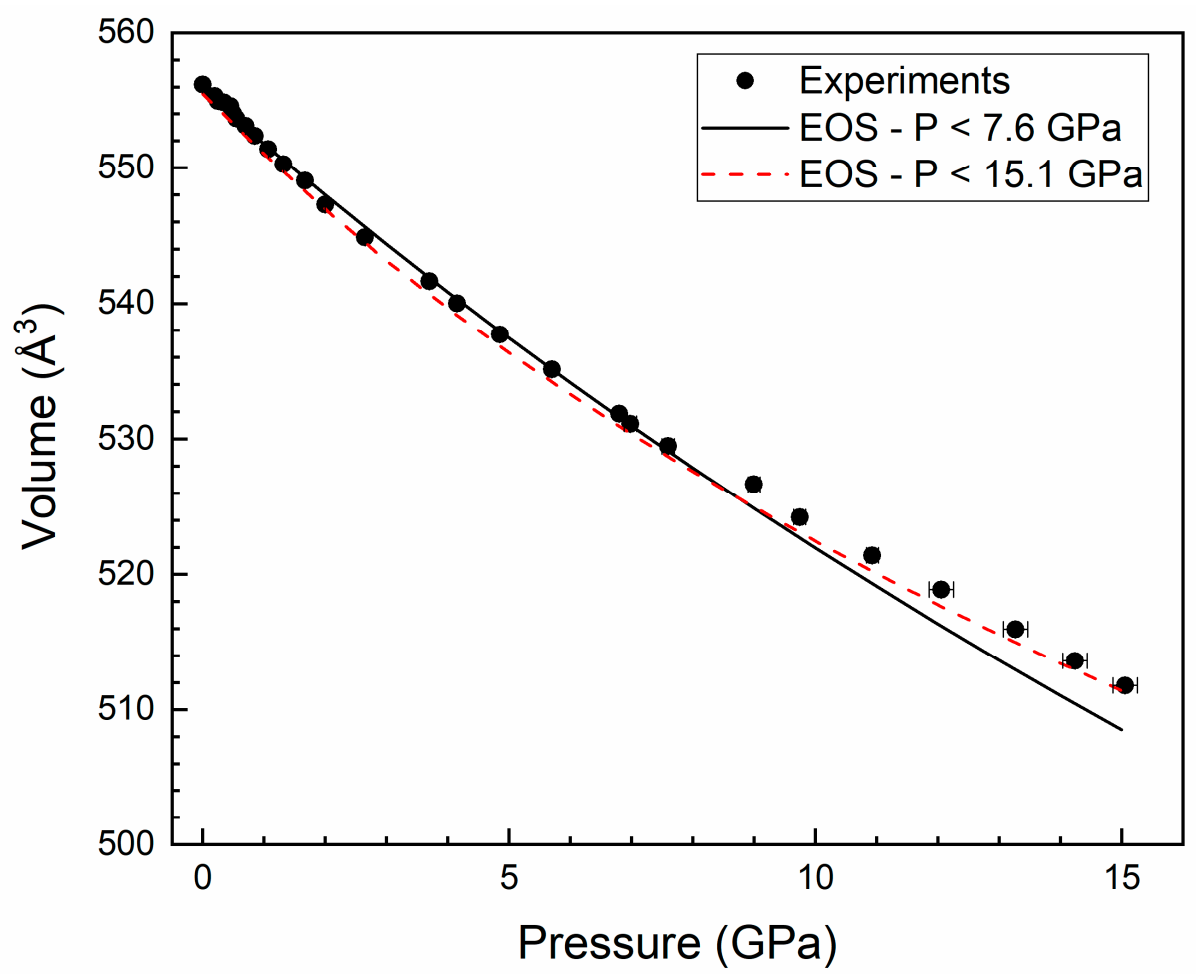

Figure 7. Pressure dependence of the unit-cell volume of $\mathrm{Ni}_{3} \mathrm{~V}_{2} \mathrm{O}_{8}$. Solid circles are obtained from experiments. Where not shown, error bars are comparable to symbols' size. The black solid (red dashed) line is the equation of state obtained from data for $P \leq 7.6$ (15.1) GPa. As stated in the text, results deviate from the quasi-hydrostatic EOS for $P \geq 7.6 \mathrm{GPa}$ likely due to the influence of non-hydrostaticity.

We will now comment on the bulk modulus of $\mathrm{Ni}_{3} \mathrm{~V}_{2} \mathrm{O}_{8}$ within the context of other $\mathrm{M}_{3} \mathrm{~V}_{2} \mathrm{O}_{8}$ vanadates $[25,26]$ using the bulk moduli summarized in Table 3 . In Table 3 , it can be seen that $\mathrm{Ni}_{3} \mathrm{~V}_{2} \mathrm{O}_{8}$ is the most incompressible compound within $\mathrm{M}_{3} \mathrm{~V}_{2} \mathrm{O}_{8}$ family of isomorphic vanadates. For the discussion, based on the fact that $\mathrm{NiO}_{6}$ units are more compressible than rigid $\mathrm{VO}_{4}$ units [10,19], we will assume 
that the bulk modulus of $\mathrm{Ni}_{3} \mathrm{~V}_{2} \mathrm{O}_{8}$ is mainly determined by the average $\mathrm{Ni}$-O distance $\left(d_{\mathrm{Ni-o}}\right)$ at ambient pressure and the formal charge of $\mathrm{Ni}\left(Z_{N i}\right)$. Such an empirical approximation works very well for ternary oxides $[27,28]$, whereby the estimated bulk modulus is given by $B_{E}=\frac{610 Z_{N i}}{d_{N i-O}}$. Using this approximation, a bulk modulus of $140 \mathrm{GPa}$ is obtained for $\mathrm{Ni}_{3} \mathrm{~V}_{2} \mathrm{O}_{8}$, which agrees within errors with the experimental value obtained from the hydrostatic-pressure regime (139(3) GPa). This suggests that the bulk modulus obtained from density-functional theory (DFT) calculations (130.4-131.2 GPa, given in Table 3) has been underestimated by $\sim 7 \%$ of the experimental value determined here. This fact is probably related to the overestimation of the ambient-pressure volume by DFT calculations [29], which is a typical feature of the general-gradient approximation used in previous computer simulations [25,26].

By using the same empirical approximation, we have estimated the bulk modulus for other $\mathrm{M}_{3} \mathrm{~V}_{2} \mathrm{O}_{8}$ vanadates, which are summarized in Table 3 for comparison with the literature. For example, in the case of $\mathrm{Zn}_{3} \mathrm{~V}_{2} \mathrm{O}_{8}$, the estimated bulk modulus is consistent with the fact that this compound has an experimentally determined bulk modulus smaller than that for $\mathrm{Ni}_{3} \mathrm{~V}_{2} \mathrm{O}_{8}$, which indicates that the approximation can be also applied to other kagome-type vanadates. In performing the empirical approximations summarized in Table 3, we found that DFT calculations have also underestimated the bulk modulus of $\mathrm{Cu}_{3} \mathrm{~V}_{2} \mathrm{O}_{8}$ and $\mathrm{Mn}_{3} \mathrm{~V}_{2} \mathrm{O}_{8}$. Using the empirical approximation, which works well for the studied vanadates, we can predict bulk moduli of 132 and $131 \mathrm{GPa}$ for $\mathrm{Mg}_{3} \mathrm{~V}_{2} \mathrm{O}_{8}$ and $\mathrm{Co}_{3} \mathrm{~V}_{2} \mathrm{O}_{8}$, respectively, which have not yet been investigated under compression. The conclusions reported in this work may be also applicable to isomorphic arsenates [30], to $(\mathrm{Ni}, \mathrm{Mg})_{3}\left(\mathrm{VO}_{4}\right)_{2}$ solid solutions [31], and to hydrated kagome-structured vanadates, such as $\mathrm{Cu}_{3} \mathrm{~V}_{2} \mathrm{O}_{7}(\mathrm{OH})_{2} \cdot 2 \mathrm{H}_{2} \mathrm{O}$ volborthite [32]. For the particular case of $\mathrm{Ni}_{3} \mathrm{As}_{2} \mathrm{O}_{8}$, a bulk modulus of $205 \mathrm{GPa}$ is predicted from the empirical model used in this work.

Table 3. Unit-cell volume, $V_{0}$, and bulk modulus, $K_{0}$, of different $\mathrm{M}_{3} \mathrm{~V}_{2} \mathrm{O}_{8}$ compounds.

\begin{tabular}{ccccc}
\hline Compound & $\mathbf{V}_{\mathbf{0}}\left(\AA^{3}\right)$ & $\begin{array}{c}\text { Experimental } \\
\boldsymbol{K}_{\mathbf{0}}(\mathbf{G P a})\end{array}$ & $\begin{array}{c}\text { Empirical } \\
\boldsymbol{K}_{\mathbf{0}}(\mathbf{G P a})\end{array}$ & $\begin{array}{c}\mathbf{D F T} \\
\left.\boldsymbol{K}_{\mathbf{0}} \mathbf{( G P a}\right)\end{array}$ \\
\hline $\mathrm{Ni}_{3} \mathrm{~V}_{2} \mathrm{O}_{8}$ & $555.5(3)$ & $139(3)^{\mathrm{a}}$ & $140^{\mathrm{c}}$ & \\
$\mathrm{Ni}_{3} \mathrm{~V}_{2} \mathrm{O}_{8}$ & 562.64 & & & $130.4-131.2^{\mathrm{b}}$ \\
$\mathrm{Mg}_{3} \mathrm{~V}_{2} \mathrm{O}_{8}$ & 576.92 & & $132^{\mathrm{c}}$ & \\
$\mathrm{Co}_{3} \mathrm{~V}_{2} \mathrm{O}_{8}$ & 578.96 & & $131^{\mathrm{c}}$ & \\
$\mathrm{Zn}_{3} \mathrm{~V}_{2} \mathrm{O}_{8}$ & $585.1(1)$ & $120(2)^{\mathrm{d}}$ & $128^{\mathrm{c}}$ & \\
$\mathrm{Cu}_{3} \mathrm{~V}_{2} \mathrm{O}_{8}$ & 586.95 & & $127^{\mathrm{c}}$ & $95-110^{\mathrm{e}}$ \\
$\mathrm{Mn}_{3} \mathrm{~V}_{2} \mathrm{O}_{8}$ & 622.1 & & $115^{\mathrm{c}}$ & $89.7-93^{\mathrm{b}}$ \\
\hline
\end{tabular}

a Calculated from X-ray diffraction (XRD) measurements here reported. ${ }^{\mathrm{b}}$ Density-functional theory (DFT) calculations [25]. ${ }^{c}$ Obtained using the empirical model described in the text. ${ }^{\mathrm{d}}$ From previous XRD experiments [7]. e DFT calculations [26].

\section{Conclusions}

Through synchrotron powder X-ray diffraction measurements, we have determined that at ambient temperature the orthorhombic kagome staircase crystal structure of $\mathrm{Ni}_{3} \mathrm{~V}_{2} \mathrm{O}_{8}$ is stable at least up to $23 \mathrm{GPa}$, the maximum pressure achieved in present experiments. We have also found that the response to compression is anisotropic. The compressibility of the $b$-axis is approximately $40 \%$ lower than the compressibility of the other axes. This special direction is perpendicular to the kagome layers, and the compression along the $b$-axis is the smallest due to the presence of incompressible $\mathrm{VO}_{4}$ tetrahedral units, which interconnect the kagome staircases of $\mathrm{NiO}_{6}$ octahedra. From the pressure dependence of the unit-cell volume we fitted a third-order Birch-Murnaghan equation of state, giving a bulk modulus of 139 (3) GPa, which is the largest among isostructural $\mathrm{M}_{3} \mathrm{~V}_{2} \mathrm{O}_{8}$ vanadates. A systematic comparison of bulk moduli in isomorphic $\mathrm{M}_{3} \mathrm{~V}_{2} \mathrm{O}_{8}$ vanadates is made based on an empirical method for predicting bulk moduli in ternary oxides. The results are consistent with those determined from experimental data here for $\mathrm{Ni}_{3} \mathrm{~V}_{2} \mathrm{O}_{8}$ and previously for $\mathrm{Zn}_{3} \mathrm{~V}_{2} \mathrm{O}_{8}$ [7]. Therefore, we also present 
predicted bulk moduli of $\mathrm{M}_{3} \mathrm{~V}_{2} \mathrm{O}_{8}$ compounds not studied yet under high pressure, $\mathrm{Co}_{3} \mathrm{~V}_{2} \mathrm{O}_{8}$ and $\mathrm{Mg}_{3} \mathrm{~V}_{2} \mathrm{O}_{8}$.

Author Contributions: Formal analysis, D.D.-A. and D.E.; Investigation, R.T., E.B. and S.A.; Methodology, D.E.; Supervision, D.E.; Writing-review \& editing, D.D.-A., R.T., E.B., S.A. and D.E. All authors have read and agreed to the published version of the manuscript.

Funding: This work was supported by the Spanish Ministry of Science, Innovation, and Universities under grants PID2019-106383GB-C41 and RED2018-102612-T (MALTA Consolider-Team network) and by Generalitat Valenciana under grant Prometeo/2018/123 (EFIMAT). R.T. acknowledges funding from the Spanish Ministry of Economy and Competitiveness MINECO) via the Juan de la Cierva Formación program (FJC2018-036185-I).

Acknowledgments: The authors thank S. N. Achary (Bhabha Atomic Research Center, India) for enlightening discussions. The authors would like to thank Diamond Light Source for beamtime provision (proposal CY21610).

Conflicts of Interest: The authors declare no conflict of interest.

\section{References}

1. Vijayakumar, S.; Lee, S.-H.; Ryu, K.-S. Synthesis of $\mathrm{Zn}_{3} \mathrm{~V}_{2} \mathrm{O}_{8}$ nanoplatelets for lithium-ion battery and supercapacitor applications. RSC Adv. 2015, 5, 91822-91828. [CrossRef]

2. Cabrera, I.; Kenzelmann, M.; Lawes, G.; Chen, Y.; Chen, W.; Erwin, R.; Gentile, T.R.; Leao, J.B.; Lynn, J.W.; Rogado, N.; et al. Coupled Magnetic and Ferroelectric Domains in Multiferroic $\mathrm{Ni}_{3} \mathrm{~V}_{2} \mathrm{O}_{8}$. Phys. Rev. Lett. 2009, 103, 087201. [CrossRef]

3. Bîrdeanu, M.-I.; Vaida, M.; Ursu, D.; Fagadar-Cosma, E. Obtaining and characterization of $\mathrm{Zn}_{3} \mathrm{~V}_{2} \mathrm{O}_{8}$ and $\mathrm{Mg}_{3} \mathrm{~V}_{2} \mathrm{O}_{8}$ pseudo binary oxide nanomaterials by hydrothermal method. In HIGH ENERGY GAMMA-RAY ASTRONOMY: 6th International Meeting on High. Energy Gamma-Ray Astronomy; AIP Publishing LLC: Melville, NY, USA, 2017; p. 030006. [CrossRef]

4. Mazloom, F.; Masjedi-Arani, M.; Salavati-Niasari, M. Novel size-controlled fabrication of pure $\mathrm{Zn}_{3} \mathrm{~V}_{2} \mathrm{O}_{8}$ nanostructures via a simple precipitation approach. J. Mater. Sci. Mater. Electron. 2015, 27, $1974-1982$. [CrossRef]

5. Qian, T.; Fan, B.; Wang, H.; Zhu, S. Structure and luminescence properties of $\mathrm{Zn}_{3} \mathrm{~V}_{2} \mathrm{O}_{8}$ yellow phosphor for white light emitting diodes. Chem. Phys. Lett. 2019, 715, 34-39. [CrossRef]

6. Liu, Y.; Li, Q.; Ma, K.; Yang, G.; Wang, C.; Qian, L. Graphene Oxide Wrapped $\mathrm{CuV}_{2} \mathrm{O}_{6}$ Nanobelts as High-Capacity and Long-Life Cathode Materials of Aqueous Zinc-Ion Batteries. ACS Nano 2019, 13, 12081-12089. [CrossRef] [PubMed]

7. Díaz-Anichtchenko, D.; Santamaria-Perez, D.; Marqueño, T.; Pellicer-Porres, J.; Ruiz-Fuertes, J.; Ribes, R.; Ibañez, J.; Achary, S.N.; Popescu, C.; Errandonea, D. Comparative study of the high-pressure behavior of $\mathrm{ZnV}_{2} \mathrm{O}_{6}, \mathrm{Zn}_{2} \mathrm{~V}_{2} \mathrm{O}_{7}$, and $\mathrm{Zn}_{3} \mathrm{~V}_{2} \mathrm{O}_{8}$. J. Alloy. Compd. 2020, 837, 155505. [CrossRef]

8. Rogado, N.; Lawes, G.; Huse, D.; Ramirez, A.; Cava, R. The Kagomé-staircase lattice: Magnetic ordering in $\mathrm{Ni}_{3} \mathrm{~V}_{2} \mathrm{O}_{8}$ and $\mathrm{Co}_{3} \mathrm{~V}_{2} \mathrm{O}_{8}$. Solid State Commun. 2002, 124, 229-233. [CrossRef]

9. Chaudhury, R.P.; Yen, F.; Cruz, C.D.; Lorenz, B.; Wang, Y.Q.; Sun, Y.Y.; Chu, C.W. Pressure-temperature phase diagram of multiferroic $\mathrm{Ni}_{3} \mathrm{~V}_{2} \mathrm{O}_{8}$. Phys. Rev. B 2007, 75, 012407. [CrossRef]

10. Errandonea, D. High pressure crystal structures of orthovanadates and their properties. J. Appl. Phys. 2020, 128, 040903. [CrossRef]

11. Errandonea, D.; Garg, A.B. Recent progress on the characterization of the high-pressure behaviour of $\mathrm{AVO}_{4}$ orthovanadates. Prog. Mater. Sci. 2018, 97, 123-169. [CrossRef]

12. Bandiello, E.; Sánchez-Martín, J.; Errandonea, D.; Bettinelli, M. Pressure Effects on the Optical Properties of $\mathrm{NdVO}_{4}$. Crystals 2019, 9, 237. [CrossRef]

13. Dewaele, A.; Loubeyre, P.; Mezouar, M. Equations of state of six metals above 94GPa. Phys. Rev. B 2004, 70 , 094112. [CrossRef]

14. Klotz, S.; Chervin, J.-C.; Munsch, P.; Le Marchand, G. Hydrostatic limits of 11 pressure transmitting media. J. Phys. D Appl. Phys. 2009, 42, 075413. [CrossRef]

15. Errandonea, D.; Meng, Y.; Somayazulu, M.; Hausermann, D. Pressure-induced alpha-to-omega transition in titanium metal: A systematic study of the effects of uniaxial stress. Physica B 2005, 355, 116-125. [CrossRef]

16. Prescher, C.; Prakapenka, V.B. DIOPTAS: A program for reduction of two-dimensional X-ray diffraction data and data exploration. High. Press. Res. 2015, 35, 223-230. [CrossRef] 
17. Sauerbrei, E.E.; Faggiani, R.; Calvo, C. Refinement of the crystal structure of $\mathrm{Co}_{3} \mathrm{~V}_{2} \mathrm{O}_{8}$ and $\mathrm{Ni}_{3} \mathrm{~V}_{2} \mathrm{O}_{8}$. Acta Crystallogr. Sect. B Struct. Crystallogr. Cryst. Chem. 1973, 29, 2304-2306. [CrossRef]

18. Errandonea, D.; Muñoz, A.; Gonzalez-Platas, J. Comment on "High-pressure x-ray diffraction study of $\mathrm{YBO}_{3} / \mathrm{Eu}^{3+}, \mathrm{GdBO}_{3}$, and $\mathrm{EuBO}_{3}$ : Pressure-induced amorphization in $\mathrm{GdBO}_{3}$ ". J. Appl. Phys. 2014, 115, 216101. [CrossRef]

19. Errandonea, D.; Ruiz-Fuertes, J. A Brief Review of the Effects of Pressure on Wolframite-Type Oxides. Crystals 2018, 8, 71. [CrossRef]

20. Laverock, J.; Piper, L.F.J.; Preston, A.R.H.; Chen, B.; McNulty, J.; Smith, K.E.; Kittiwatanakul, S.; Lu, J.W.; Wolf, S.A.; Glans, P.-A.; et al. Strain dependence of bonding and hybridization across the metal-insulator transition of $\mathrm{VO}_{2}$. Phys. Rev. B 2012, 85, 081104. [CrossRef]

21. Zhang, Y.; Qiu, X.; Fang, D. Mechanical Properties of two novel planar lattice structures. Int. J. Solids Struct. 2008, 45, 3751-3768. [CrossRef]

22. Turnbull, R.; Errandonea, D.; Cuenca-Gotor, V.P.; Sans, J.Á.; Gomis, O.; Gonzalez, A.; Rodríguez-Hernandez, P.; Popescu, C.; Bettinelli, M.; Mishra, K.K.; et al. Experimental and theoretical study of dense $\mathrm{YBO}_{3}$ and the influence of non-hydrostaticity. J. Alloy. Compd. 2021, 850, 156562. [CrossRef]

23. Birch, F. Finite elastic strain of cubic crystals. Phys. Rev. 1947, 71, 809-824. [CrossRef]

24. Gonzalez-Platas, J.; Alvaro, M.; Nestola, F.; Angel, R.J. EosFit7-GUI: A new GUI tool for equation of state calculations, analyses, and teaching. J. Appl. Crystallogr. 2016, 49, 1377-1382. [CrossRef]

25. Koc, H.; Palaz, S.; Mamedov, A.M.; Ozbay, E. Electronic and elastic properties of the multiferroic crystals with the Kagome type lattices $-\mathrm{Mn}_{3} \mathrm{~V}_{2} \mathrm{O}_{8}$ and $\mathrm{Ni}_{3} \mathrm{~V}_{2} \mathrm{O}_{8}$ : First principle calculations. Ferroelectrics 2019, 544, 11-19. [CrossRef]

26. Jezierski, A.; Kaczkowski, J. Electronic structure and thermodynamic properties of $\mathrm{Cu}_{3} \mathrm{~V}_{2} \mathrm{O}_{8}$ compound. Phase Transit. 2015, 88, 1-9. [CrossRef]

27. Errandonea, D.; Manjón, F.J. Pressure effects on the structural and electronic properties of $\mathrm{ABX}_{4}$ scintillating crystals. Prog. Mater. Sci. 2008, 53, 711-773. [CrossRef]

28. Errandonea, D.; Muñoz, A.; Rodríguez-Hernández, P.; Gomis, O.; Achary, S.N.; Popescu, C.; Patwe, S.J.; Tyagi, A.K. High-Pressure Crystal Structure, Lattice Vibrations, and Band Structure of $\mathrm{BiSbO}_{4}$. Inorg. Chem. 2016, 55, 4958-4969.

29. Zhang, G.-X.; Reilly, A.M.; Tkatchenko, A.; Scheffler, M. Performance of various density-functional approximations for cohesive properties of 64 bulk solids. New J. Phys. 2018, 20, 063020. [CrossRef]

30. Barbier, J.; Frampton, C. Structures of orthorhombic and monoclinic $\mathrm{Ni}_{3}\left(\mathrm{AsO}_{4}\right)_{2}$. Acta Crystallogr. Sect. B Struct. Sci. 1991, 47, 457-462. [CrossRef]

31. Nord, A.G.; Werner, P.-E. Cation distribution studies of three (Ni, Mg) orthovanadates. Zeitschrift für Kristallographie - Crystalline Materials 1991, 194, 49. [CrossRef]

32. Wang, P.; Yang, H.; Wang, D.; Chen, Y.; Dai, W.L.; Zhao, X.; Yang, J.; Wang, X. Activation of kagome lattice-structured $\mathrm{Cu}_{3} \mathrm{~V}_{2} \mathrm{O}_{7}(\mathrm{OH})_{2} \cdot 2 \mathrm{H}_{2} \mathrm{O}$ volborthite via hydrothermal crystallization for boosting visible light-driven water oxidation. Phys. Chem. Chem. Phys. 2018, 20, 24561-24569. [CrossRef] [PubMed]

(C) 2020 by the authors. Licensee MDPI, Basel, Switzerland. This article is an open access article distributed under the terms and conditions of the Creative Commons Attribution (CC BY) license (http://creativecommons.org/licenses/by/4.0/). 